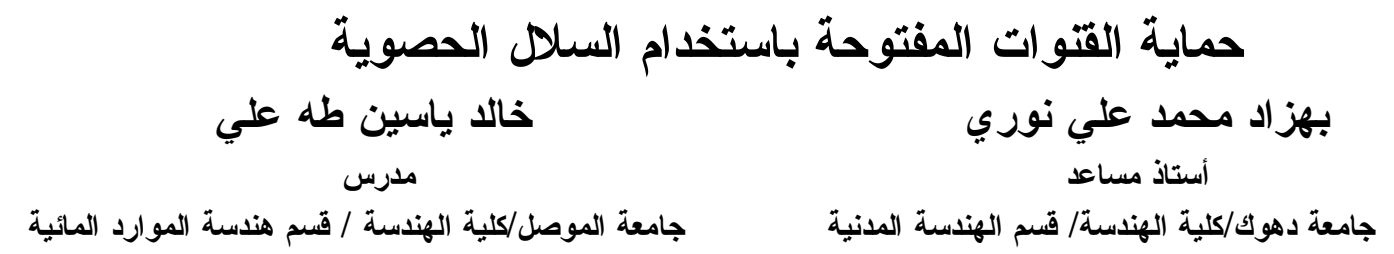

الخلاصة

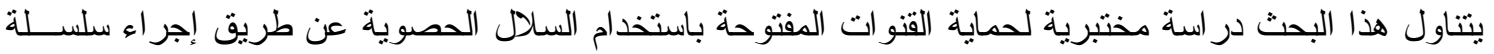

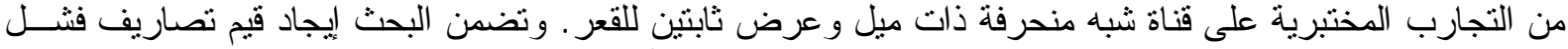

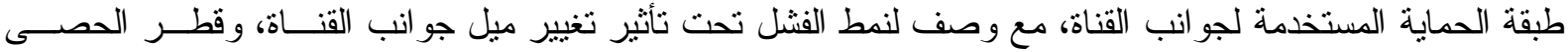

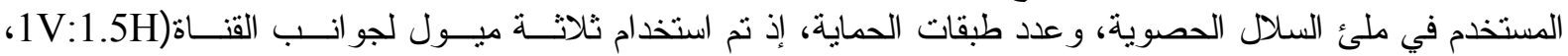
و 1V:2.5H 1V:2H

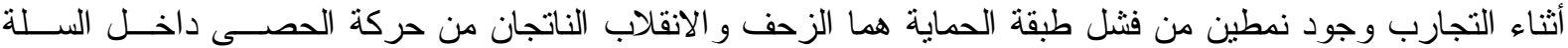
الحصوية.

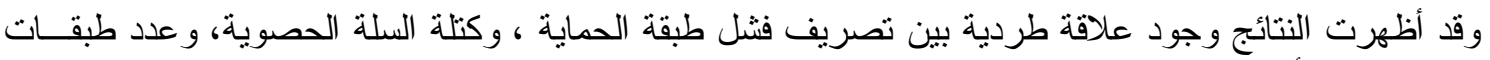

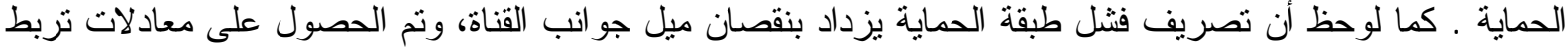

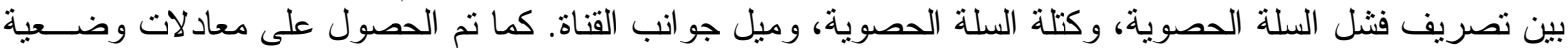

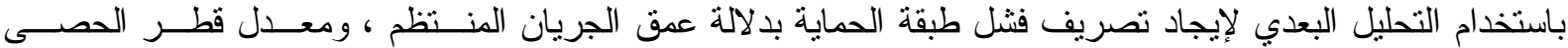

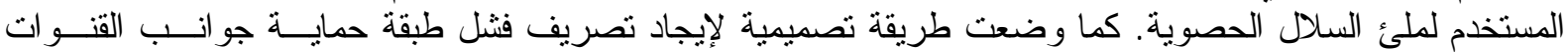
باستخدام السلال الحصوية. الكلمات الدالة: القنو ات المفتوحة، السلال الصخرية.

\title{
Protection Of Open Channels Using Gabions
}

\section{Bahzad Mohammad Ali Noori}

Assistant Lecturer

\section{Khalid Yassin Taha Ali}

Lecturer

\begin{abstract}
This research investigates open channel protection using gabions by conducting a series of laboratory tests on a trapezoidal channel with fixed width and bed slope. In this study, values of failure flowrates are obtained with a description of failure mode under the effect of changing channel side slope, gravel mean diameter, and number of protection layers. Three channel side slopes are tested $(1 \mathrm{~V}: 1.5 \mathrm{H}, 1 \mathrm{~V}: 2 \mathrm{H}$, and $1 \mathrm{~V}: 2.5 \mathrm{H})$, with three gravel diameters $(11.1,15.9$, and 22.25)mm, for one and two layers of protection. Two modes of failure have been observed namely sliding and overturning due to the movement of gravel inside the gabions.

Results showed a direct relation between failure flowrate of protection layer and both gabion weight and number of protection layers. It has been obtained that failure flow rate increases with the decrease of channel side slopes. Equations have been obtained relating failure flowrate with both gabion weight and channel side slope. Empirical equations have been obtained using dimensional analysis to estimate failure flowrate as a function of uniform flow depth and gravel mean diameter. A design method has been proposed to protect channel side slopes using gabions.
\end{abstract}

Keywords: open channels, gabions 


\section{1}

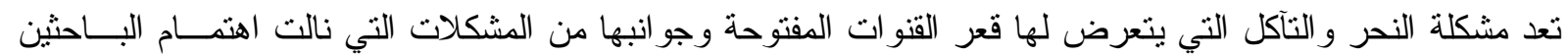

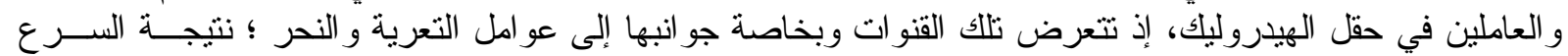

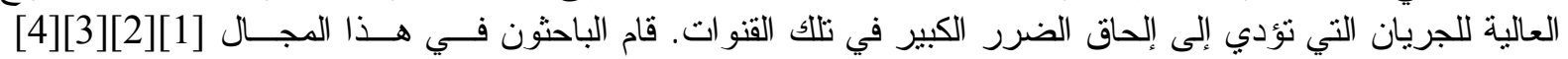

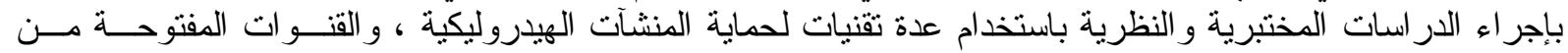

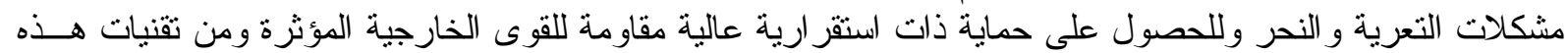

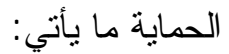

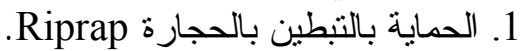

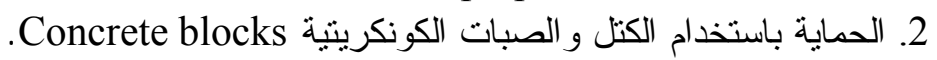

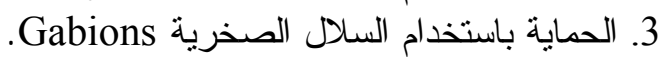

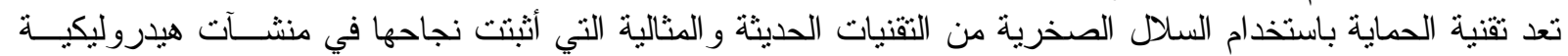

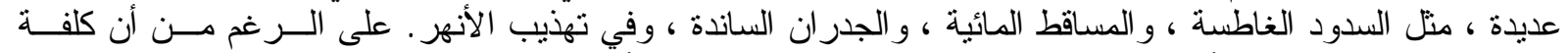

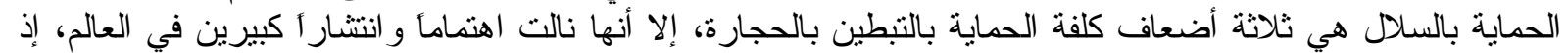

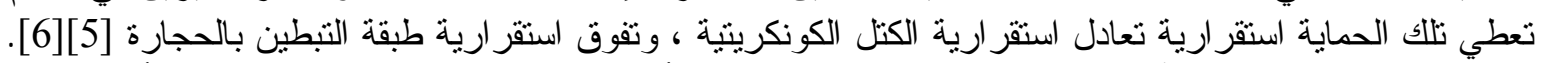

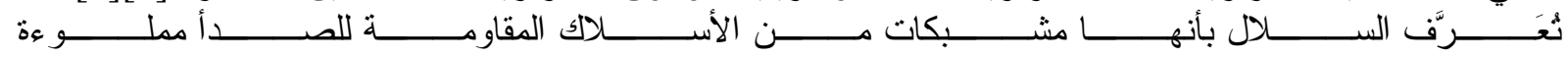

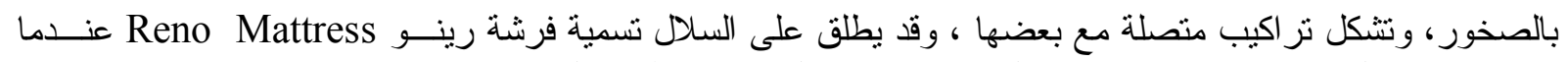

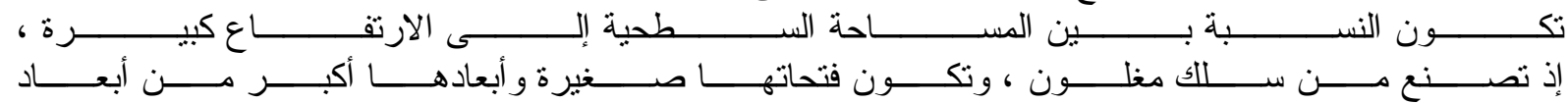

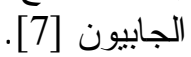

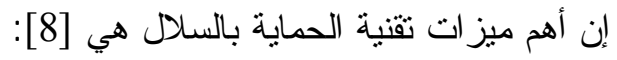

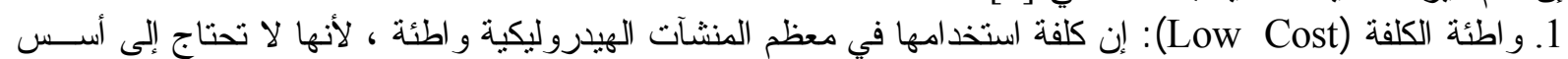

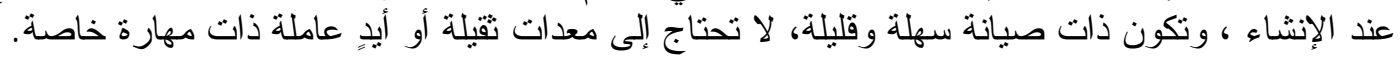

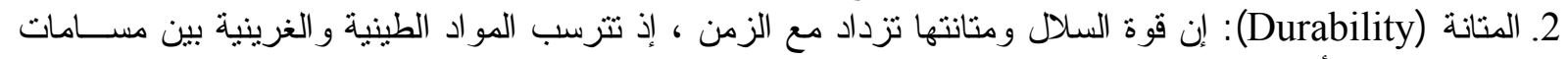

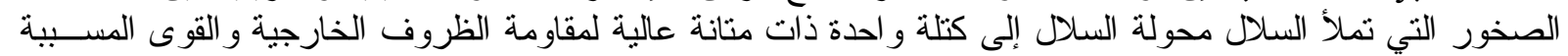
لفشلها.

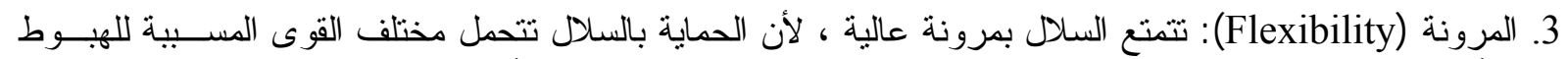

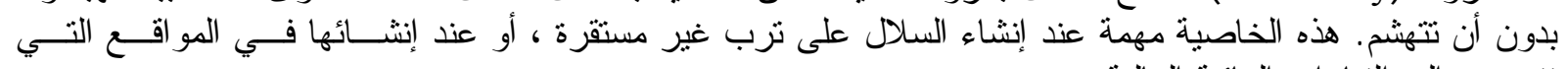
تتعرض إلى التيار ات المائية العالية .

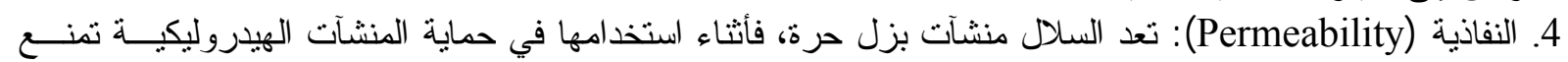
تكون الثحنات الساكنة (Hydrostatic heads) خلفها. فضلا عن الميزات المذكورة في أعلاه تعمل السلال على إدامة البيئة إذ تسمح للنباتات بالنمو من خلالها مما يزيد مـنـ مقاومتها وتضيف جاذبية وجمال للموقع.

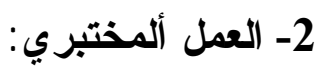

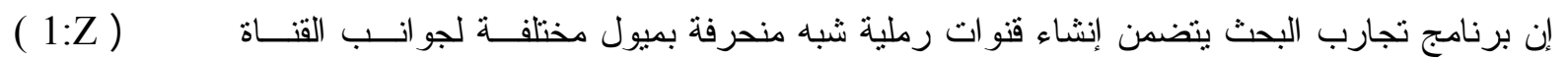

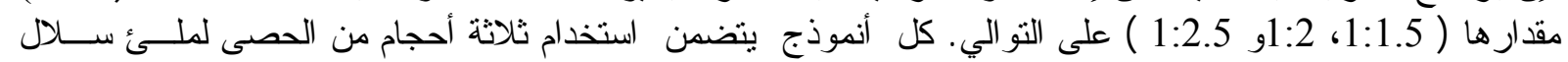

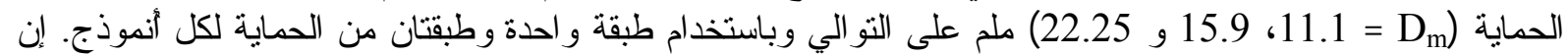

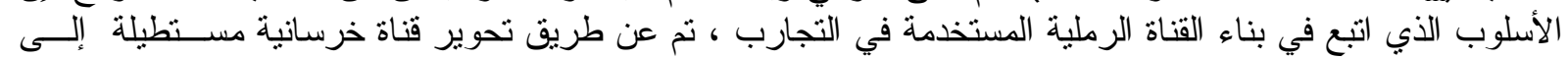

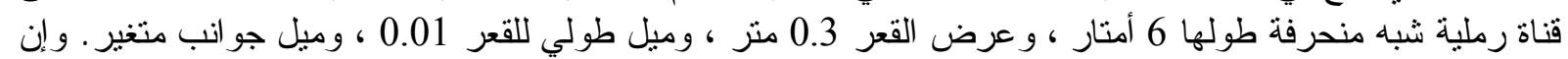

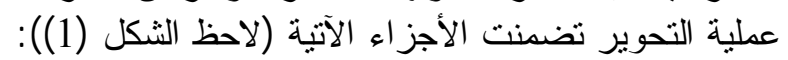

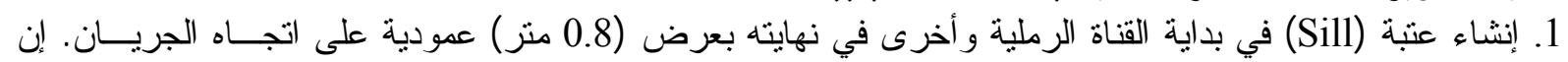

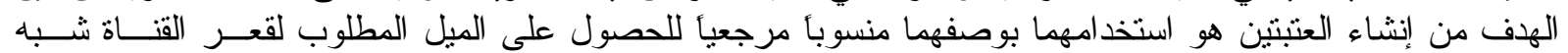
المنحرفة.

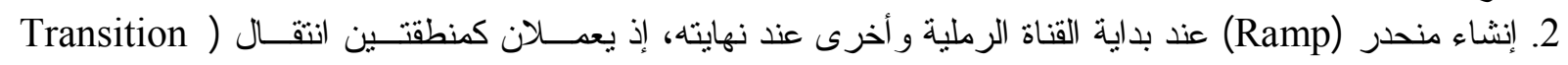
Zones

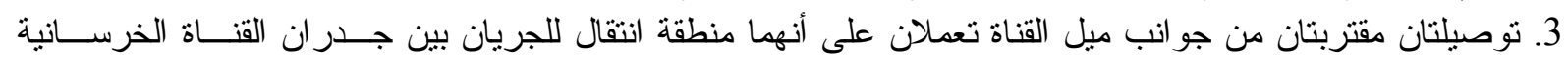

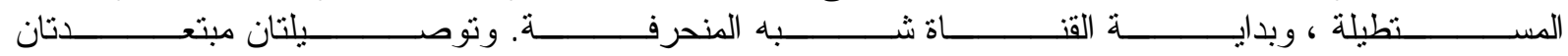


عن جو انب ميل القناة تعملان على أنهما منطقة انتقال للجريان من نهاية القناة شبه المنحرفة إلى جدر ان القناة الخرسانية

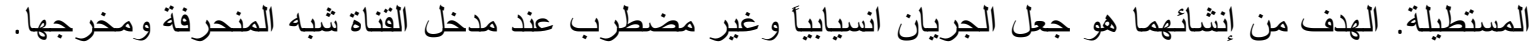

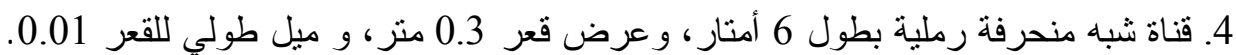

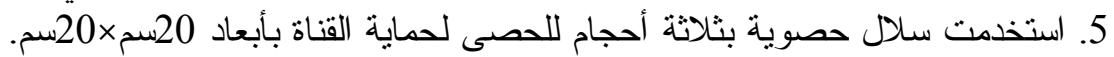

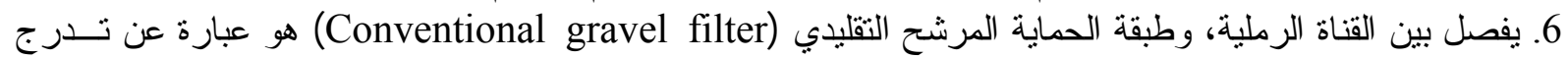

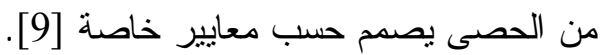

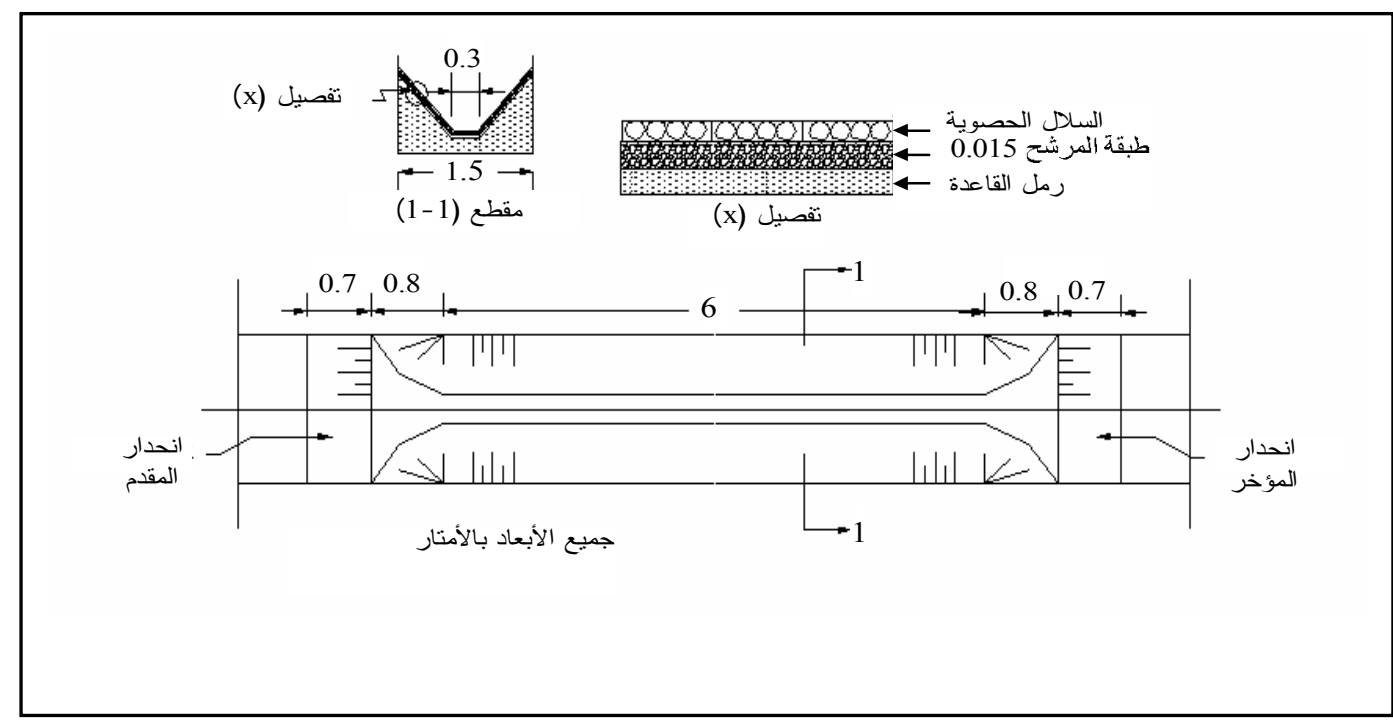

الثكل (1): منظور أفقي للقتاة الرملية مع مقطع عرضي

\section{3 - مواصفات المواد المستخدمة في التجارب: \\ 1.3 مواصفات الحصى (Gravel Specifications):}

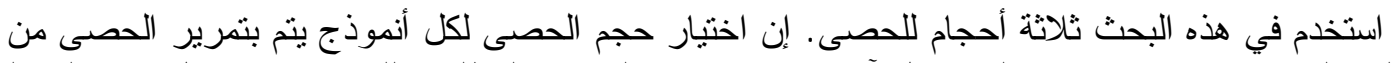

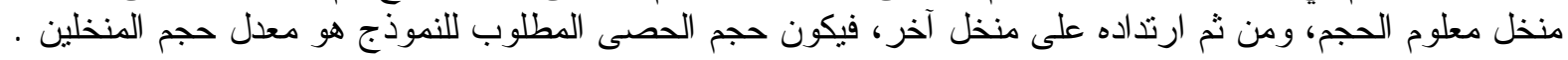

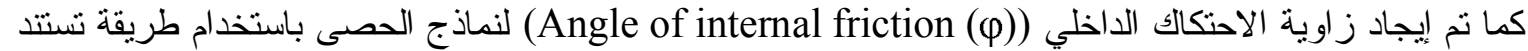

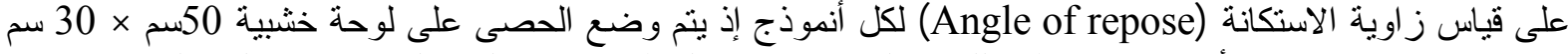

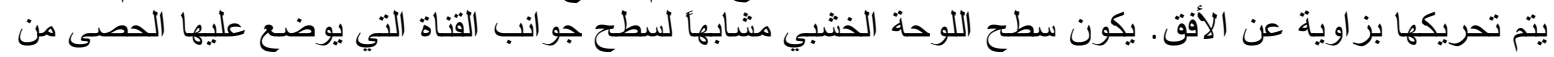

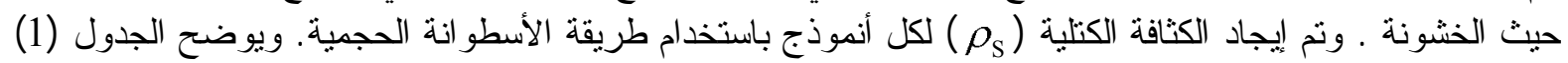
مو اصفات الحصى المستخدم في التجارب المختبرية.

الجدول (1): مواصفات الحصى المستخدم في التجارب

\begin{tabular}{|c|c|c|c|c|c|}
\hline زالداية الاحتكاك & 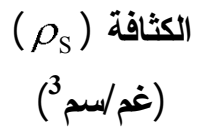 & $\begin{array}{l}D_{m} \\
\text { (ملم) }\end{array}$ & يرتا على المنخل & 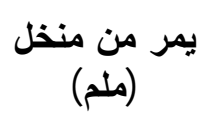 & الأنموذّ \\
\hline 34.4 & 2.623 & 11.1 & 9.5 & 12.7 & الأول \\
\hline 35.7 & 2.648 & 15.9 & 12.7 & 19.1 & الثاني \\
\hline 37 & 2.688 & 22.25 & 19.1 & 25.4 & الثالث \\
\hline
\end{tabular}


3. 2 مواصفات السلال الحصوية (Gabions Specifications):

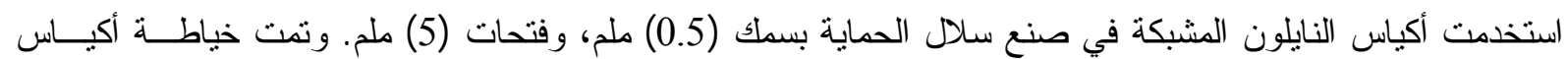

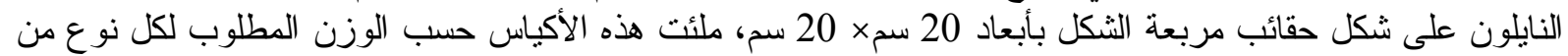

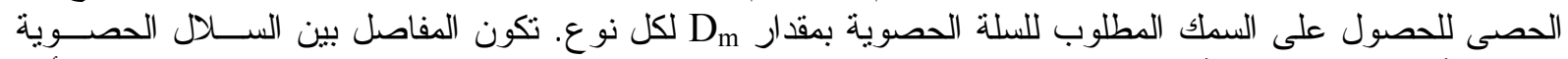

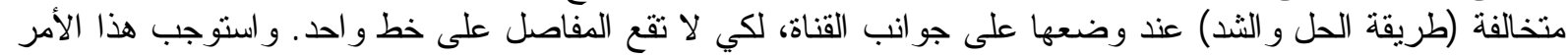

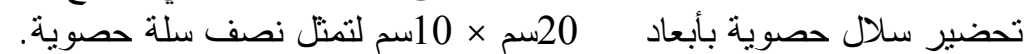

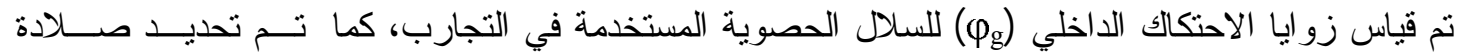

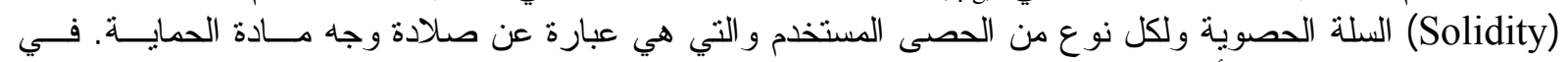

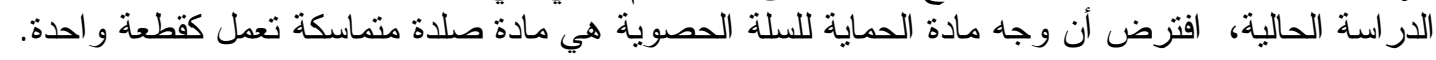

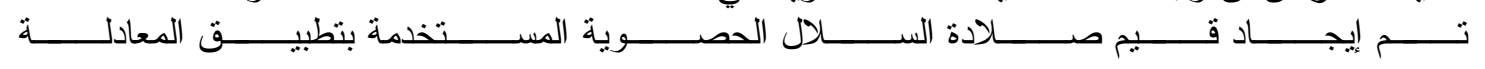
$\mathrm{a}=\frac{\mathrm{W}_{\mathrm{g}}}{\mathrm{x} \cdot l \cdot \rho_{\mathrm{S}} \cdot \mathrm{d}}$ الآتية [10]:

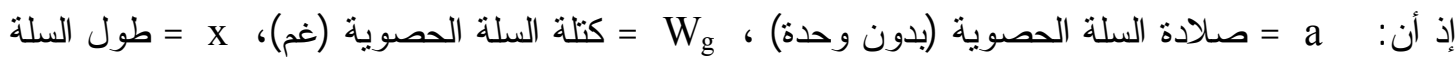
الحصوية (سم)، = = عرض السلة الحصوية (سم)،

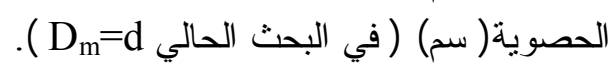
الجدول (2) يوضح مو اصفات السّلد الحصوية المستخدمة في التجارب. الجدول (2): مو اصفات السلال الحصوية المستخدمة في التجارب

\begin{tabular}{|c|c|c|c|}
\hline زاويـة الاحتكاك الداخلي & الصلادة(a) & الكتلة W (غر م) (غر) & D \\
\hline 35 & 0.6011 & 700 & 1.11 \\
\hline 36.3 & 0.5344 & 900 & 15.9 \\
\hline 38.5 & 0.5225 & 1250 & 22.25 \\
\hline
\end{tabular}

بعد تهيئة القناة المختبرية لإجر اء التجارب، وضعت السلال الحصوية على القناة الرملية بالطريقة الموضحة في الثكل

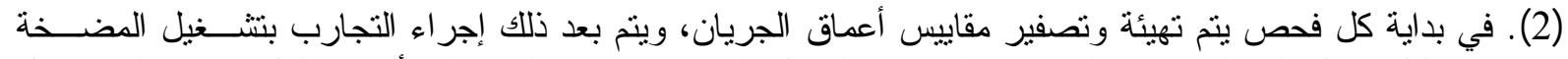
وبجريان قليل يدخل إلى القناة شبه المنحرفة المحمية بالسلاد الحصوية.

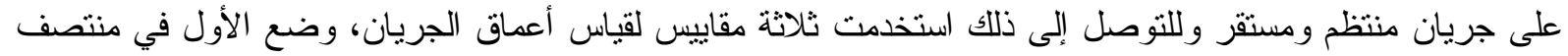

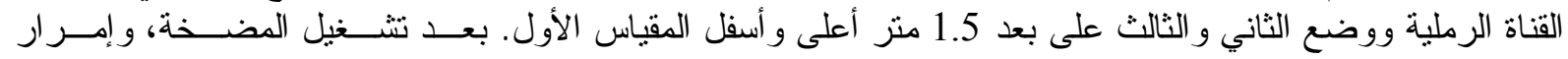

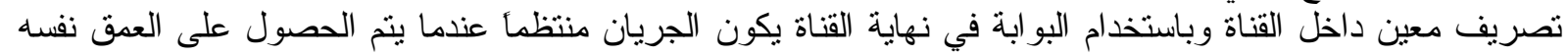

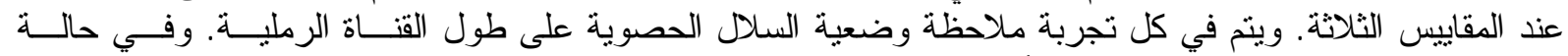

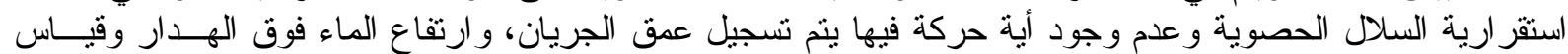

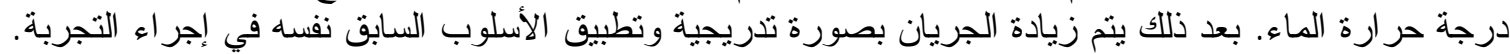

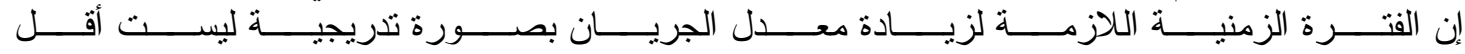

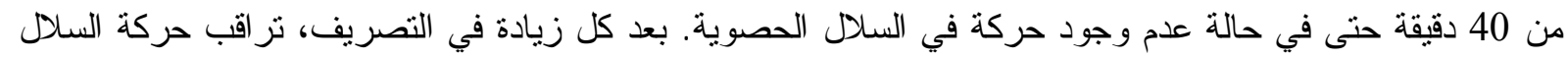

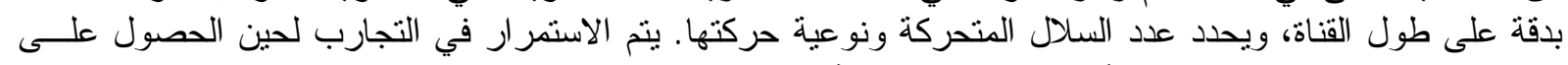

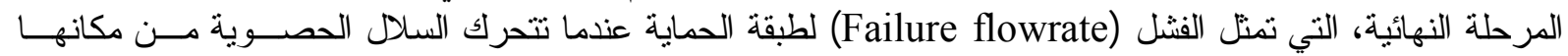

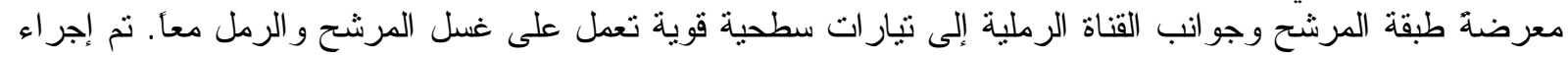

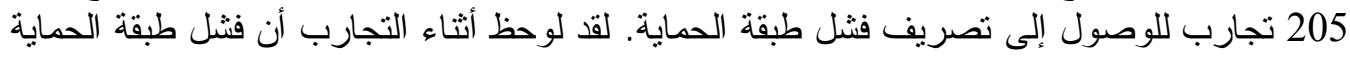




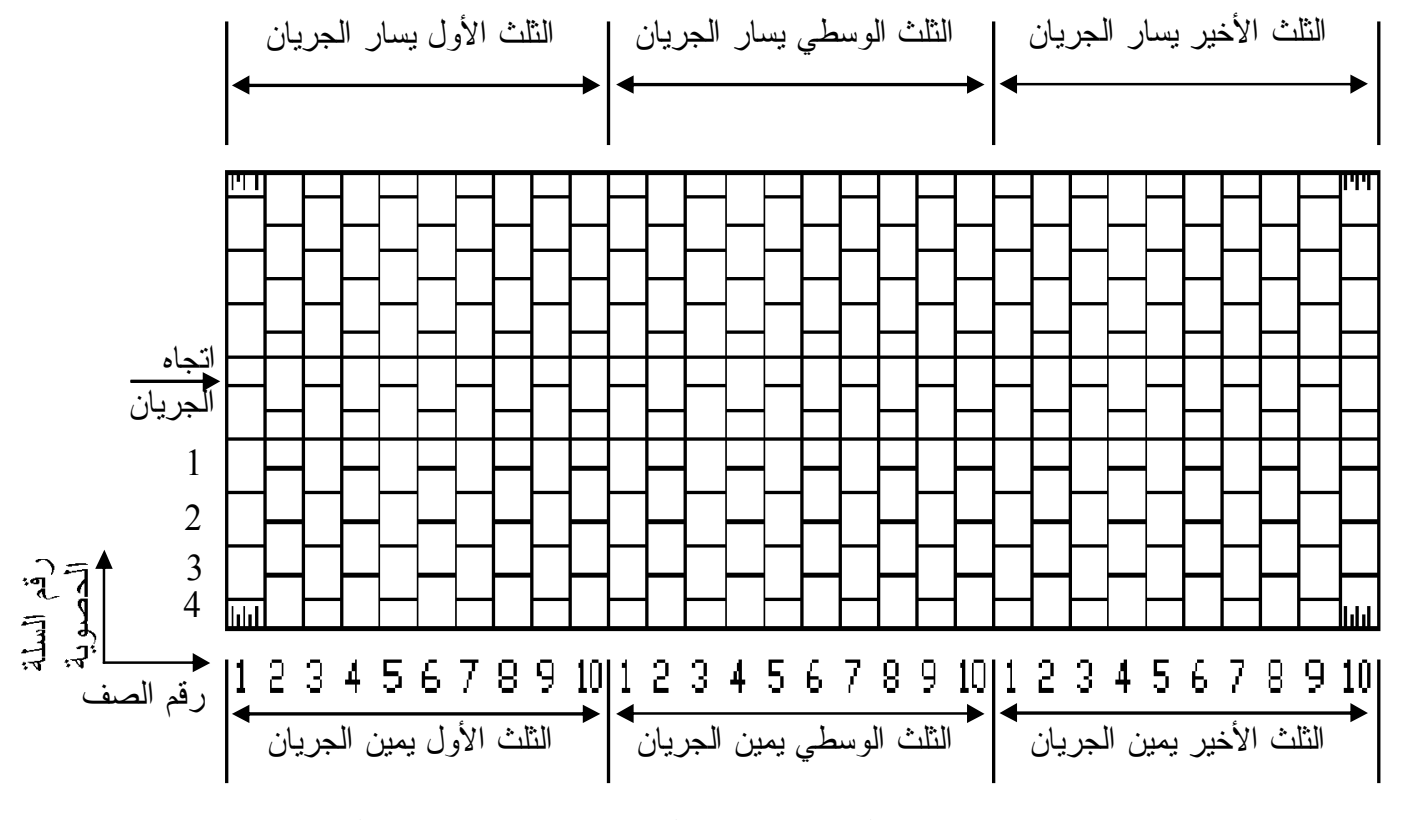

الشكل (2): المنظور الأفقي للقتاة الرملبة يوضح طريقة وضع السلال الحصوية على القتاة

بيدأ أو لا باهتز از السلة الحصوية من موقعها اهتز از آ موقعيأ بسيطا، ومن ثم يبدأ الحصى داخل السلة بالحركة

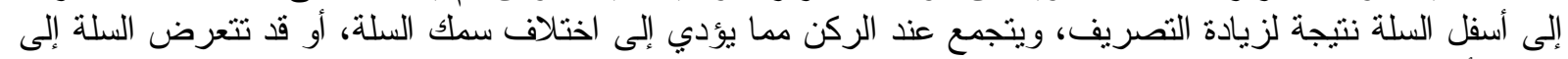

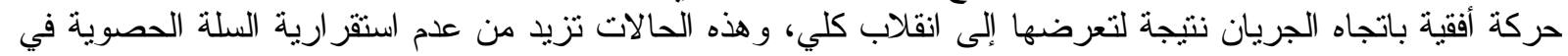

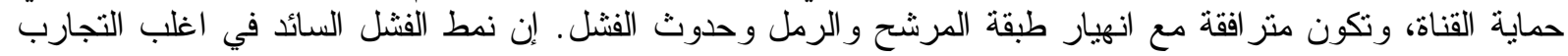

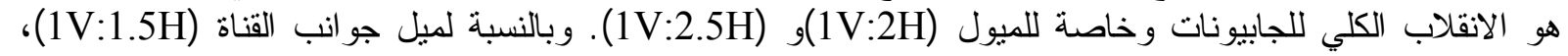

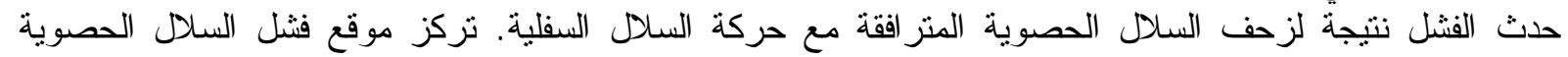

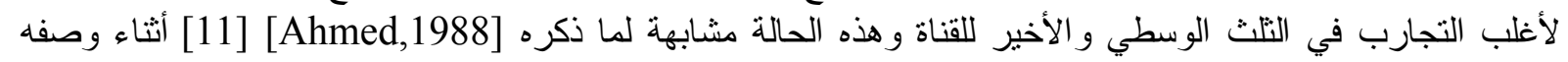

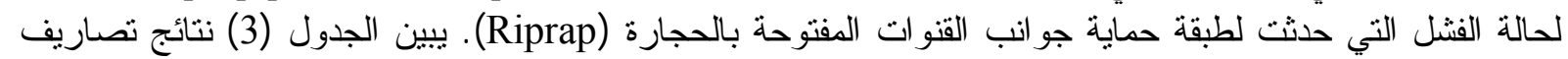
فنشل الحماية بالسلال الحصل التصوية.

4. تحليل النتائج المختبرية ومناقشتها: إن تحليل النتائج المختبرية تم بوساطة دراسة العوامل امل المؤثرة في تصريف فنثل الحماية بالسلال الحصوية ثلثم استخدام طريقة التحليل البعدي لنتلك العو امل للحصول على معادلة عامة لتصريف فنثل الحماية بالسلال الحصوية.

\section{4 العو امل المؤثرة في تصريف الفثل:}

1.1.4 كتلة السلال الحصوية (Wg):

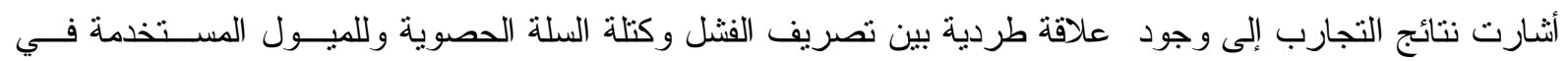

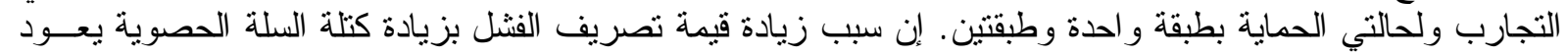

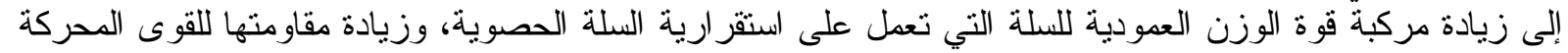

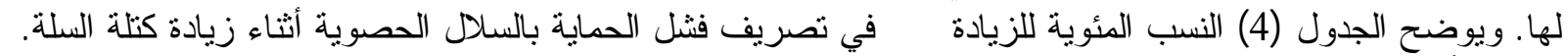

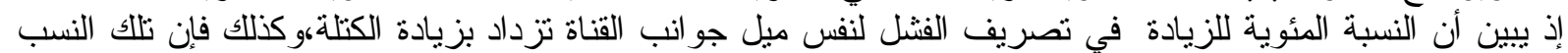

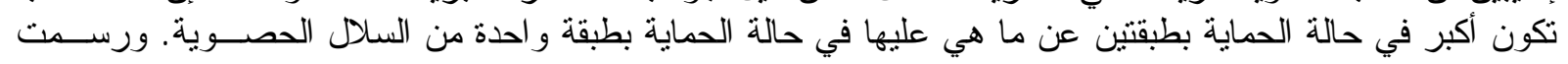
العلاقة بين تصريف الفشل وكتلة السلة الحصوية ولحالتي الحماية بطبقة واحدة وطبقتنين في الثكلين (3 -أ) و و(3 -بة). 
الجدول (3): تصاريف فثل الحماية بالسلال الحصوية

\begin{tabular}{|c|c|c|c|c|c|c|}
\hline تصريف الفثل & عدد طبقات & $\begin{array}{c}\text { درجة حر ارة } \\
\text { (الماء } \\
\left(C^{\circ}\right)\end{array}$ & الجريان & ميل جوانب & كتلة السلة & معدل قطر \\
\hline 63.691 & 1 & 14 & 0.154 & $1: 1.5$ & 0.7 & 0.0111 \\
\hline 75.442 & 1 & 12 & 0.165 & $1: 1.5$ & 0.9 & 0.0159 \\
\hline 97.819 & 1 & 13 & 0.189 & $1: 1.5$ & 1.25 & 0.02225 \\
\hline 71.440 & 1 & 16 & 0.147 & $1: 2$ & 0.7 & 0.0111 \\
\hline 86.880 & 1 & 16 & 0.166 & $1: 2$ & 0.9 & 0.0159 \\
\hline 106.935 & 1 & 21 & 0.185 & $1: 2$ & 1.25 & 0.02225 \\
\hline 77.475 & 1 & 25 & 0.151 & $1: 2.5$ & 0.7 & 0.0111 \\
\hline 96.705 & 1 & 27 & 0.17 & $1: 2.5$ & 0.9 & 0.0159 \\
\hline 118.783 & 1 & 25 & 0.192 & $1: 2.5$ & 1.25 & 0.02225 \\
\hline 68.494 & 2 & 14 & 0.167 & $1: 1.5$ & 0.7 & 0.0111 \\
\hline 92.285 & 2 & 13 & 0.18 & $1: 1.5$ & 0.9 & 0.0159 \\
\hline 112.797 & 2 & 14 & 0.208 & $1: 1.5$ & 1.25 & 0.02225 \\
\hline 79.528 & 2 & 15 & 0.158 & $1: 2$ & 0.7 & 0.0111 \\
\hline 96.702 & 2 & 16 & 0.175 & $1: 2$ & 0.9 & 0.0159 \\
\hline 122.434 & 2 & 21 & 0.2 & $1: 2$ & 1.25 & 0.02225 \\
\hline 83.698 & 2 & 24 & 0.153 & $1: 2.5$ & 0.7 & 0.0111 \\
\hline 108.098 & 2 & 27 & 0.182 & $1: 2.5$ & 0.9 & 0.0159 \\
\hline 129.870 & 2 & 26 & 0.2 & $1: 2.5$ & 1.25 & 0.02225 \\
\hline
\end{tabular}

الجدول (4): النسب المئوية للزيادة في تصريف الفثل بزيادة كتلة السلة الحصوية

\begin{tabular}{|c|c|c|c|c|}
\hline 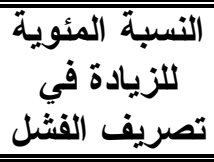 & تغيير تصريف الفشل & زيادة كتلة السلة & عدد طبقات الحماية & القتاة (1:Z) \\
\hline 18.5 & $75.442-63.691$ & $0.9-0.7$ & \multirow{2}{*}{1} & \multirow{2}{*}{$1: 1.5$} \\
\hline 53.6 & $97.819-63.691$ & $1.25-0.7$ & & \\
\hline 21.6 & $86.88-71.44$ & $0.9-0.7$ & \multirow{2}{*}{1} & \multirow{2}{*}{$1: 2$} \\
\hline 49.7 & $106.935-71.44$ & $1.25-0.7$ & & \\
\hline 24.8 & $96.705-77.475$ & $0.9-0.7$ & \multirow{2}{*}{1} & \multirow{2}{*}{$1: 2.5$} \\
\hline 53.3 & $118.783-77.475$ & $1.25-0.7$ & & \\
\hline 34.7 & $92.285-68.494$ & $0.9-0.7$ & \multirow{2}{*}{2} & \multirow{2}{*}{$1: 1.5$} \\
\hline 64.7 & $112.797-68.494$ & $1.25-0.7$ & & \\
\hline 21.6 & $96.702-79.528$ & $0.9-0.7$ & \multirow{2}{*}{2} & \multirow{2}{*}{$1: 2$} \\
\hline 54 & $122.434-79.528$ & $1.25-0.7$ & & \\
\hline 29.2 & $108.098-83.698$ & $0.9-0.7$ & \multirow{3}{*}{2} & \multirow{3}{*}{$1: 2.5$} \\
\hline & & & & \\
\hline 55.2 & $129.87-83.698$ & $1.25-0.7$ & & \\
\hline
\end{tabular}



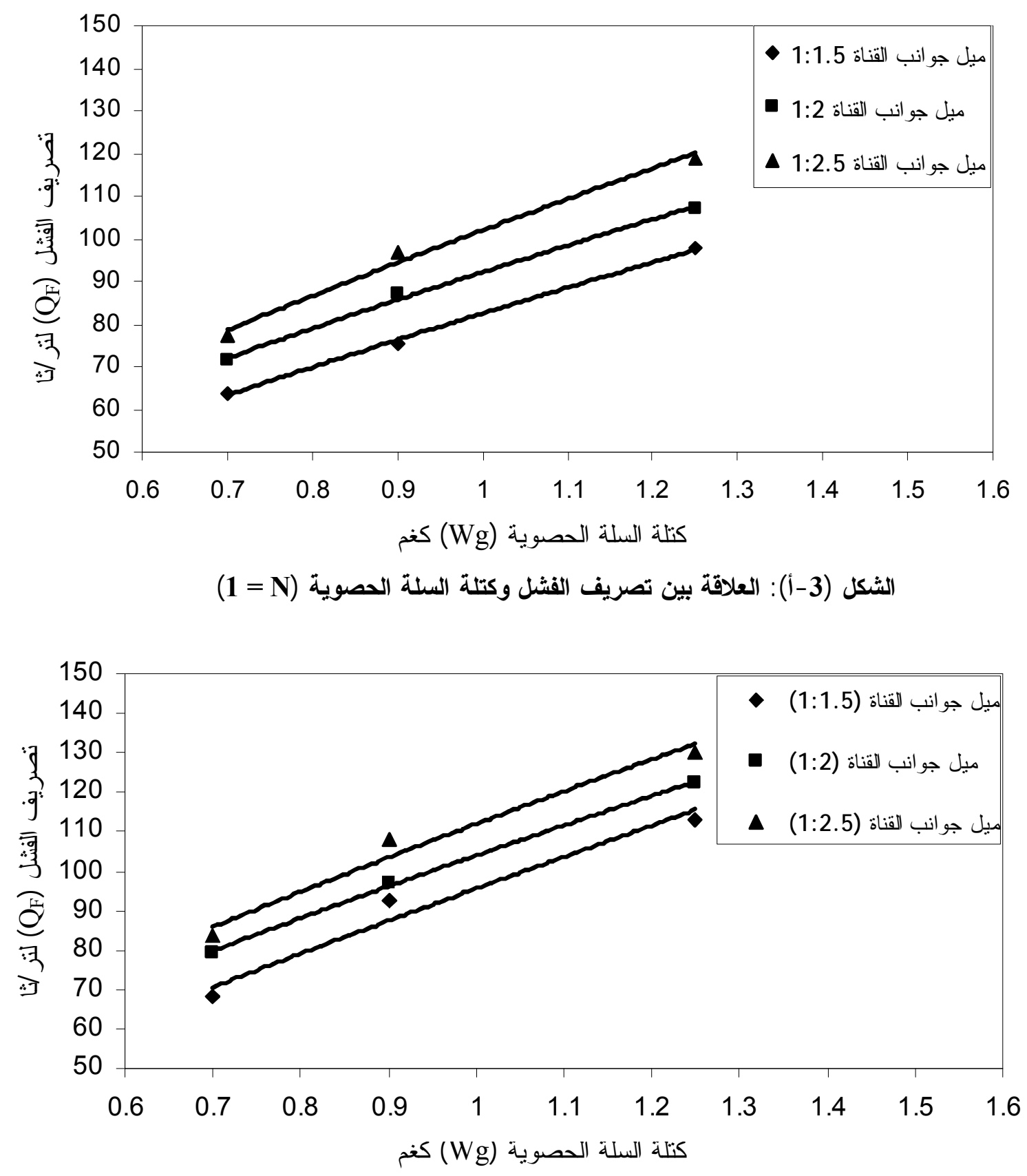

الثكل (3 -ب): العلاقة بين تصريف الفشل وكتلة السلة الحصوية (2 = 2)

نم الحصول على العلاقة الأتية التي تربط تصريف الفشل وكتلة السلة:

$\mathrm{Q}_{\mathrm{F}}=\mathrm{a}_{1} \mathrm{Wg}^{\mathrm{n}_{1}}$

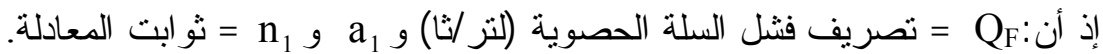

$$
\begin{aligned}
& \text { يبين الجدول (5) قيم الثوابت a و مع مع معامل التحديد }
\end{aligned}
$$


الجدول (5): قيم الثوابت a و n مع معامل التحديد

\begin{tabular}{|c|c|c|c|c|}
\hline $\begin{array}{c}\text { معامل التحديد } \\
\text { R }^{2} \\
\end{array}$ & $\mathrm{n}_{1}$ & $a_{1}$ & عدد طبقات /الحماية & ميل جو/انب القتاة \\
\hline 0.98 & 0.743 & 82.49 & 1 & $1: 1.5$ \\
\hline 0.99 & 0.693 & 92.17 & 1 & $1: 2$ \\
\hline 0.99 & 0.732 & 101.96 & 1 & $1: 2.5$ \\
\hline 0.96 & 0.848 & 95.58 & 2 & $1: 1.5$ \\
\hline 0.99 & 0.743 & 103.99 & 2 & $1: 2$ \\
\hline 0.97 & 0.747 & 112 & 2 & $1: 2.5$ \\
\hline
\end{tabular}

$$
\text { 2.1.4 ميل جوانب القتاة (S=1/Z) }
$$

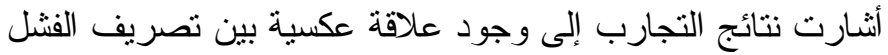

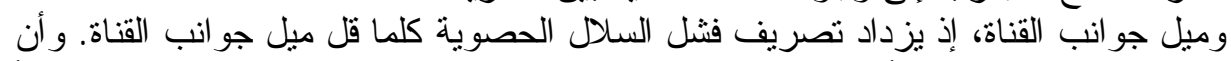

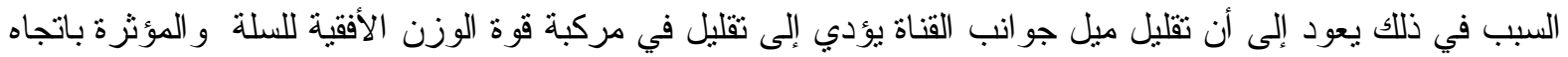

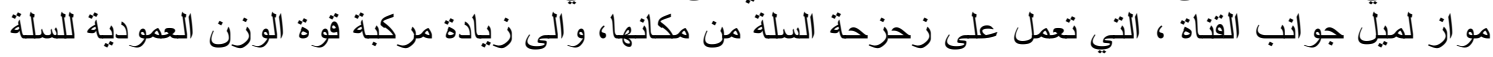

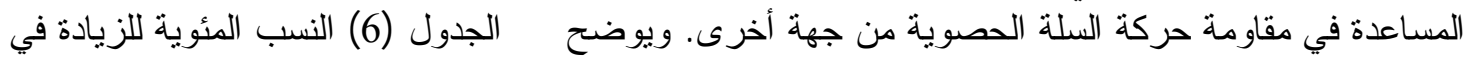
تصريف فثل السلال الحصوية بتقليل ميل جو انب القناة. الجدول (6): النسب المئوية للزيادة في تصريف الفشل بتقليل ميل جو انب القناة

\begin{tabular}{|c|c|c|c|c|}
\hline للزيادة في تصريف النئوية & تغيير تصريف الفشل & 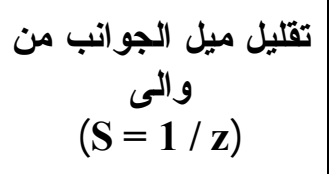 & عبد طبقات & الكتئة السئة \\
\hline 12.2 & 71.44- 63.691 & $0.5-0.6666$ & \multirow{2}{*}{1} & \multirow{2}{*}{0.7} \\
\hline 21.7 & $77.475-63.691$ & $0.4-0.6666$ & & \\
\hline 15.2 & $86.88-75.442$ & $0.5-0.6666$ & \multirow{2}{*}{1} & \multirow{2}{*}{0.9} \\
\hline 28.2 & $96.705-75.442$ & $0.4-0.6666$ & & \\
\hline 9.3 & $106.935-97.819$ & $0.5-0.6666$ & \multirow{2}{*}{1} & \multirow{2}{*}{1.25} \\
\hline 21.4 & $118.783-97.819$ & $0.4-0.6666$ & & \\
\hline 16.1 & $79.528-68.494$ & $0.5-0.6666$ & \multirow{2}{*}{2} & \multirow{2}{*}{0.7} \\
\hline 22.2 & $83.698-68.494$ & $0.4-0.6666$ & & \\
\hline 4.8 & $96.702-92.285$ & $0.5-0.6666$ & \multirow{2}{*}{2} & \multirow{2}{*}{0.9} \\
\hline 17.1 & $108.048-92.285$ & $0.4-0.6666$ & & \\
\hline 8.5 & $122.434-112.797$ & $0.5-0.6666$ & \multirow{2}{*}{2} & \multirow{2}{*}{1.25} \\
\hline 15.1 & $129.87-112.797$ & $0.4-0.6666$ & & \\
\hline
\end{tabular}




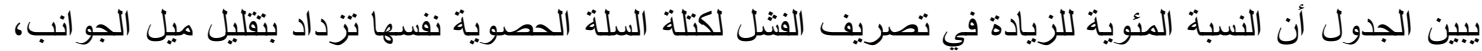
ولحالتي الحماية بطبقة و احدة وطبقتين من السلال الحصوية. رسمت العلاقة بين تصريف الفشل، وميل جو انب القناة في الثكلين (4 - أ) و(4 -ب).

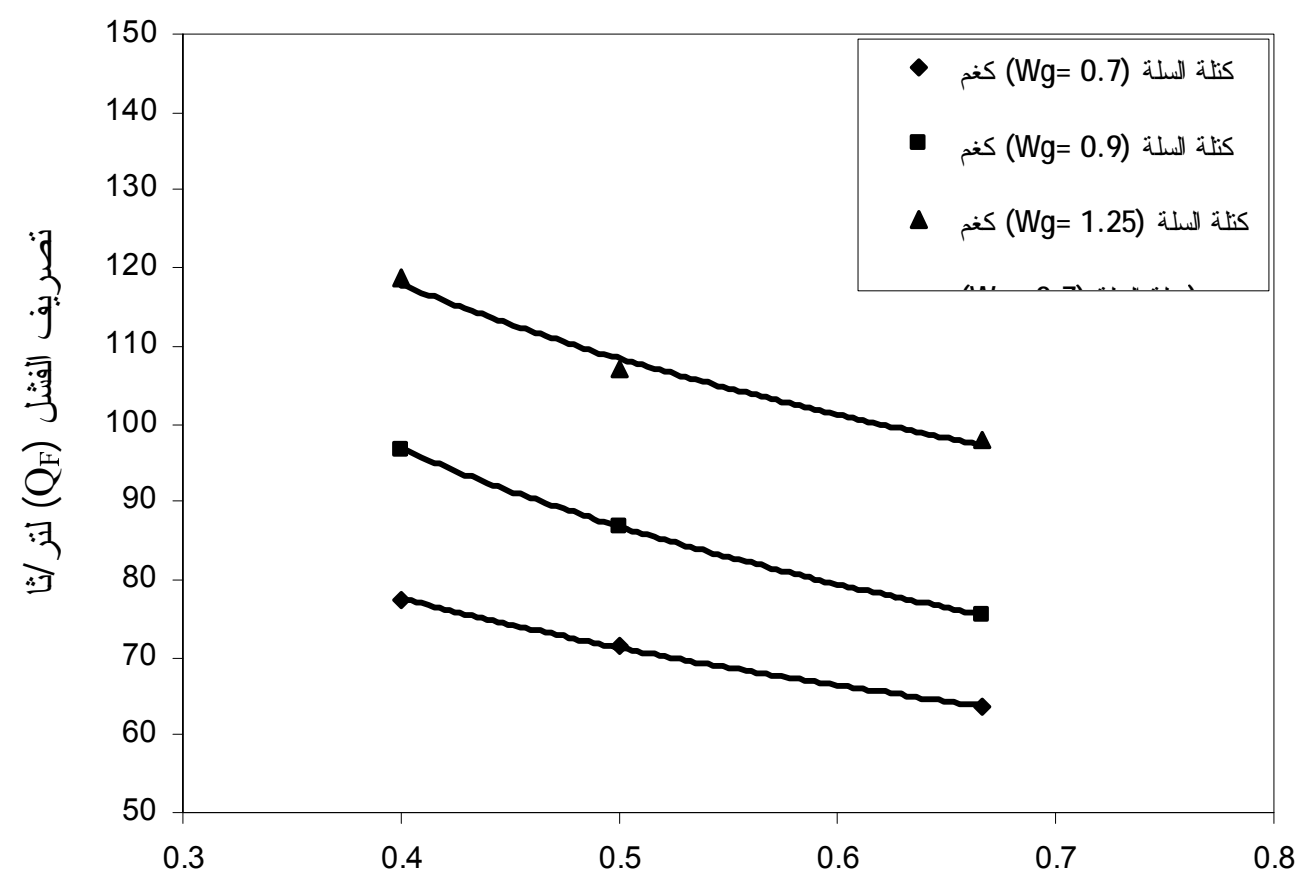

(S) ميل جو انب القناة

الثكل (4 -)): العلاقة بين تصريف الفشل وميل جواتب القتاة (S = (1)

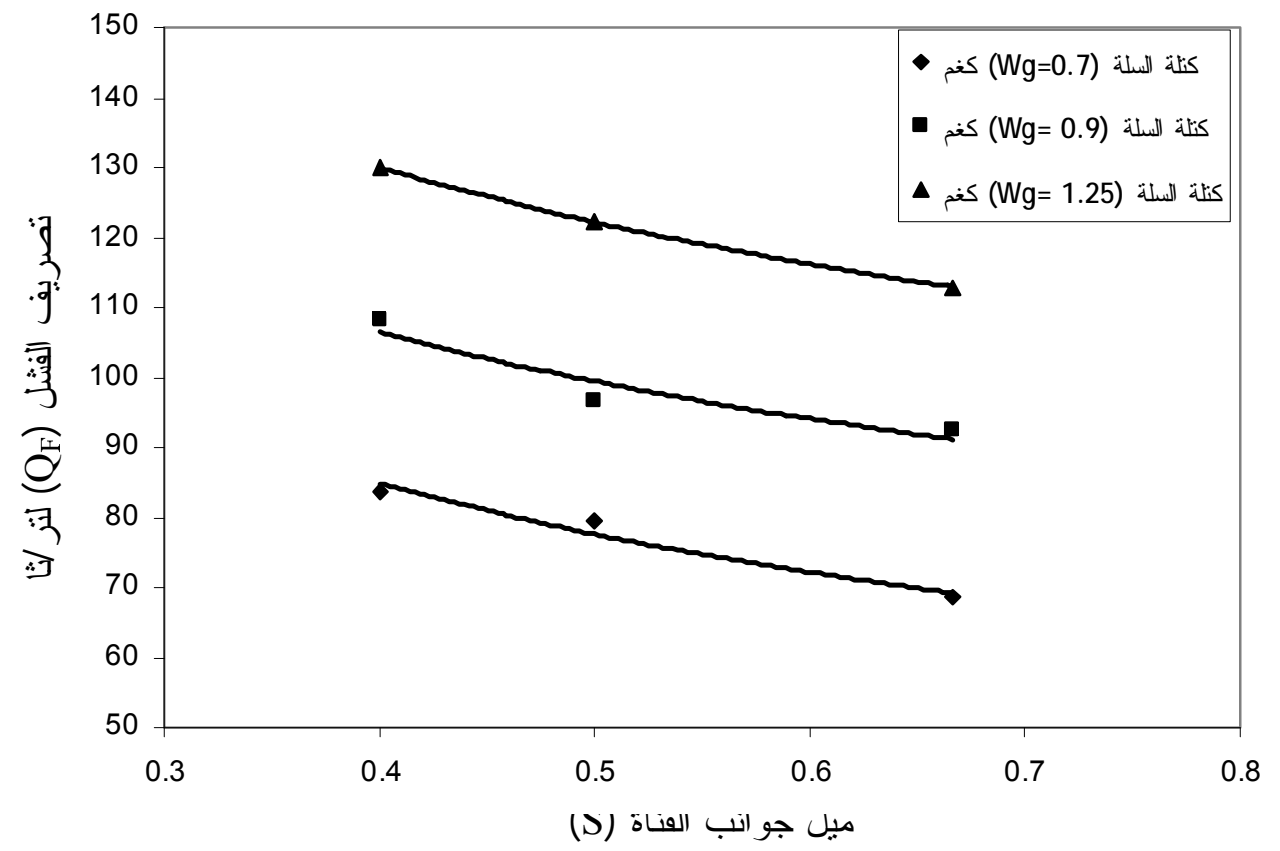

الثكل (4 -ب): العلاقة بين تصريف الفشل وميل جوانب القتاة (2 = )

تم الحصول على العلاقة الأتية التي تربط تصريف الفشل وميل جو انب القناة:

$\mathrm{Q}_{\mathrm{F}}=\mathrm{a}_{2} \mathrm{~S}^{\mathrm{n}_{2}}$

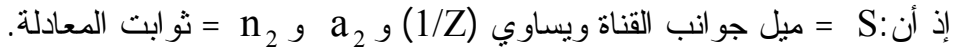

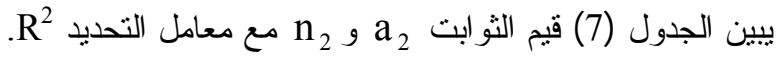




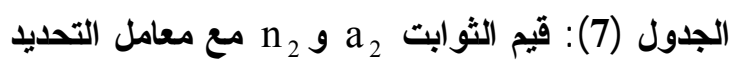

\begin{tabular}{|c|c|c|c|c|}
\hline معامل التحديد & $\mathrm{n}_{2}$ & $a_{2}$ & عثد طبقات الحماية. & 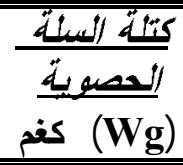 \\
\hline 0.98 & -0.391 & 54.39 & 1 & 0.7 \\
\hline 0.99 & -0.494 & 61.70 & 1 & 0.9 \\
\hline 0.98 & -0.383 & 83.22 & 1 & 1.25 \\
\hline 0.95 & -0.399 & 58.89 & 2 & 0.7 \\
\hline 0.91 & -0.303 & 80.63 & 2 & 0.9 \\
\hline 0.99 & -0.276 & 100.91 & 2 & 1.25 \\
\hline
\end{tabular}

3.1.4

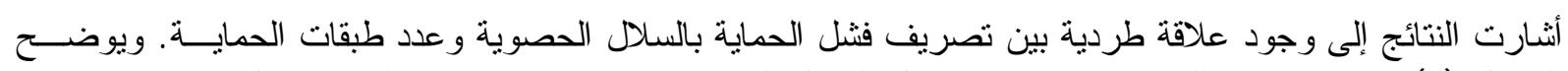

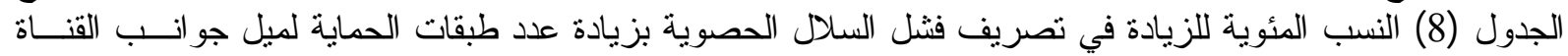

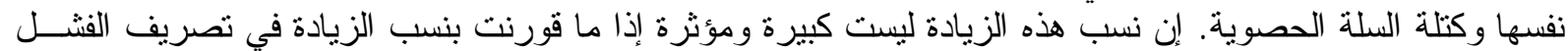

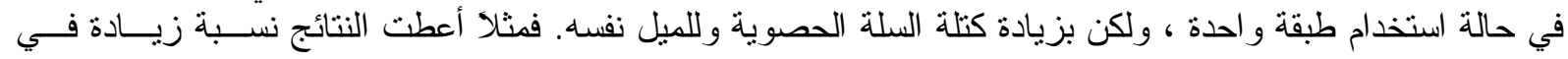

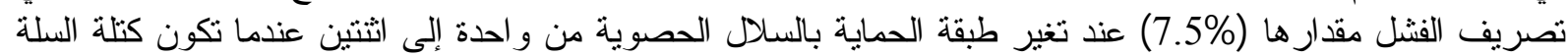

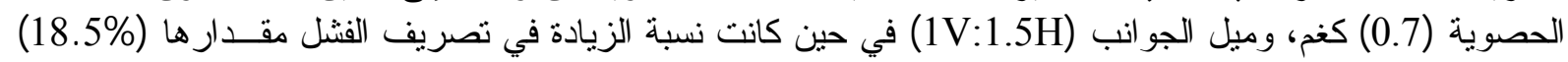

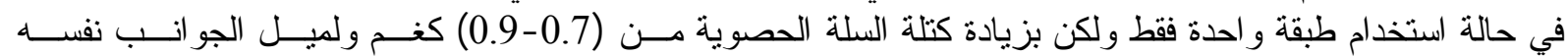

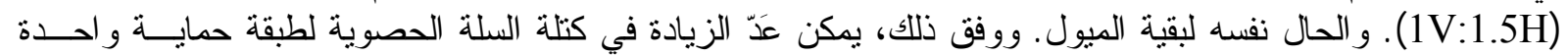

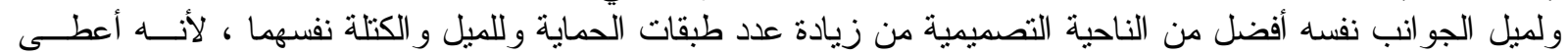

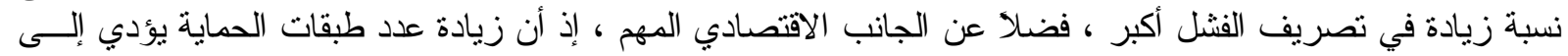
كلفة اكبر من كلفة تغيير كتلة السلة الحصوية. الجدول (8): النسب المئوية للزيادة في تصريف الفنل بزيادة عدد طبقات الحماية

\begin{tabular}{|c|c|c|c|c|}
\hline تصريف النسبة فئئية & 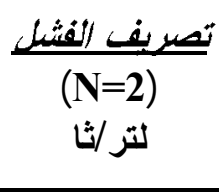 & $\begin{array}{c}\text { تصريف الفشثل } \\
\text { (N=1) } \\
\text { لتر/ثاث }\end{array}$ & ميل جوانب القتاة & كتلة السيلة \\
\hline 7.5 & 68.494 & 63.691 & $1: 1.5$ & 0.7 \\
\hline 22.3 & 92.285 & 75.442 & $1: 1.5$ & 0.9 \\
\hline 15.3 & 112.797 & 97.819 & $1: 1.5$ & 1.25 \\
\hline 11.3 & 79.528 & 71.44 & $1: 2$ & 0.7 \\
\hline 11.3 & 96.702 & 86.88 & $1: 2$ & 0.9 \\
\hline 14.5 & 122.434 & 106.935 & $1: 2$ & 1.25 \\
\hline 8 & 83.698 & 77.457 & $1: 2.5$ & 0.7 \\
\hline 11.8 & 108.098 & 96.705 & $1: 2.5$ & 0.9 \\
\hline 9.3 & 129.870 & 118.783 & $1: 2.5$ & 1.25 \\
\hline
\end{tabular}




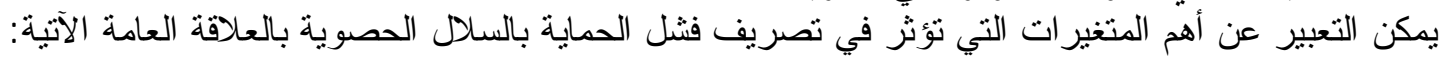

$Q_{F}=f\left(D_{m}, y, g, \rho_{s}-\rho_{w}, \rho_{w}, S, S_{g}, a, N\right)$

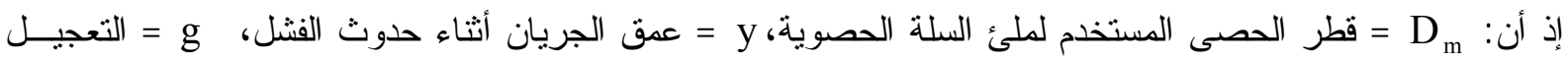
الأرضي، السكون للسلة الحصوية a a

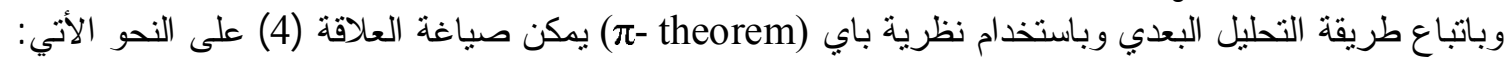

$$
\mathrm{f}_{1}\left(\frac{\mathrm{Q}_{\mathrm{F}}}{\mathrm{y}^{2.5} \mathrm{~g}^{0.5}}, \frac{\mathrm{y}}{\mathrm{D}_{\mathrm{m}}}, \mathrm{S}, \rho^{\prime}, \mathrm{S}, \mathrm{a}, \mathrm{N}\right)=0
$$

إذ أن : في حد لا بعدي و احد ، وباعادة ترتيب المتغير ات في العلاقة (5) يمكن كتابتها بالثنكل الأتي:

$\mathrm{Q}_{\mathrm{F}}=\mathrm{C} \mathrm{y}^{2.5} \mathrm{~g}^{0.5}\left(\frac{\mathrm{y}}{\mathrm{D}_{\mathrm{m}}}\right)^{\mathrm{X} 1}\left(\rho^{\prime} \mathrm{aS} \mathrm{g}\right)^{\mathrm{X} 2}(\mathrm{~S})^{\mathrm{X} 3}(\mathrm{~N})^{\mathrm{X} 4}$

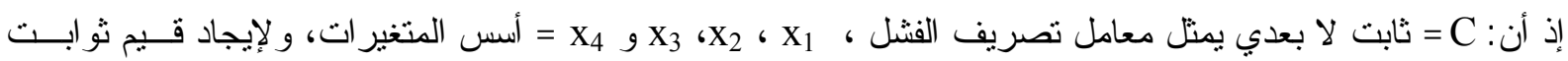

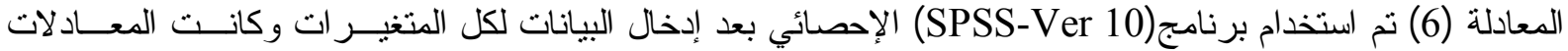
بالثكل الآتي:

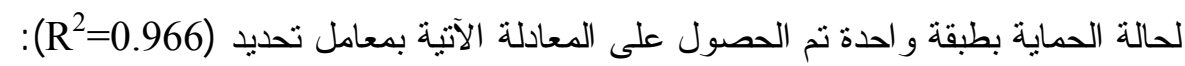

$\mathrm{Q}_{\mathrm{F}}=0.877 \mathrm{y}^{2.5} \mathrm{~g}^{0.5}\left(\frac{\mathrm{y}}{\mathrm{D}_{\mathrm{m}}}\right)^{0.278}\left(\rho^{\prime} \mathrm{aS}_{\mathrm{g}}\right)^{-0.294}(\mathrm{~S})^{-0.342}$

$$
\text { لحالة الحماية بطبقتين نم الحصول على المعادلة الآتية بمعامل تحديد (R2=0.93): }
$$

$\mathrm{Q}_{\mathrm{F}}=0.717 \mathrm{y}^{2.5} \mathrm{~g}^{0.5}\left(\frac{\mathrm{y}}{\mathrm{D}_{\mathrm{m}}}\right)^{0.269}\left(\rho^{\prime} \mathrm{aS} \mathrm{g}^{-0.446}(\mathrm{~S})^{-0.485}\right.$

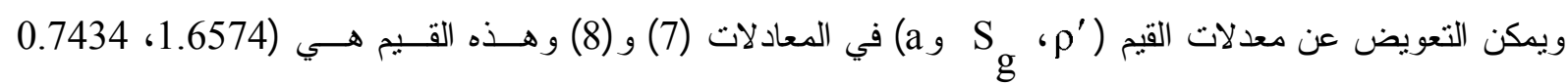
و 0.5527) على التو الي، و التعويض عن قيمة التعجيل الأرضي (9.81 = g g) م/ثا2 وبعد التبسيط تصبح تلاك المعادلات

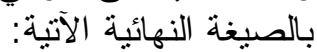
لحالة الحماية بطبقة و احدة:

$\mathrm{Q}_{\mathrm{F}}=3.075 \frac{\mathrm{y}^{2.778} \mathrm{~S}^{-0.342}}{\mathrm{D}_{\mathrm{m}}^{0.278}}$

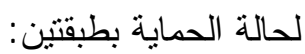

$\mathrm{Q}_{\mathrm{F}}=2.666 \frac{\mathrm{y}^{2.769} \mathrm{~S}^{-0.485}}{\mathrm{D}_{\mathrm{m}}^{0.269}}$

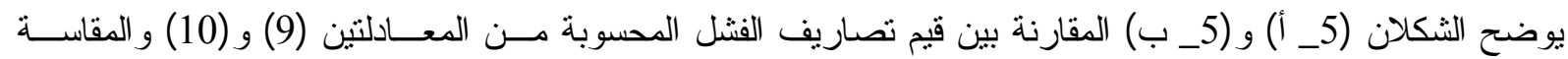

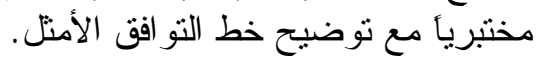




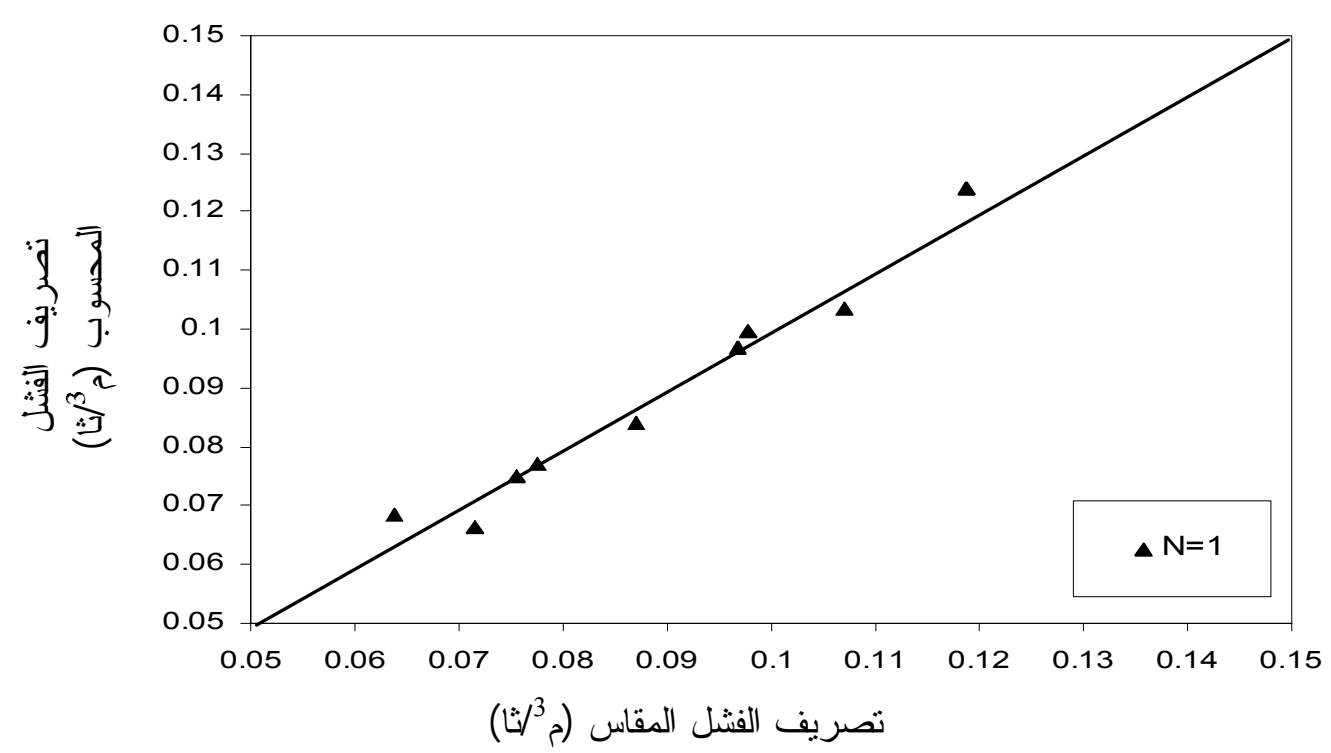

الثكل (5 - أ): مقارنة بين قيم تصاريف فثل السلال الحصوية المحسوبة من المعادلة (9) و المقاسة مختبرياً

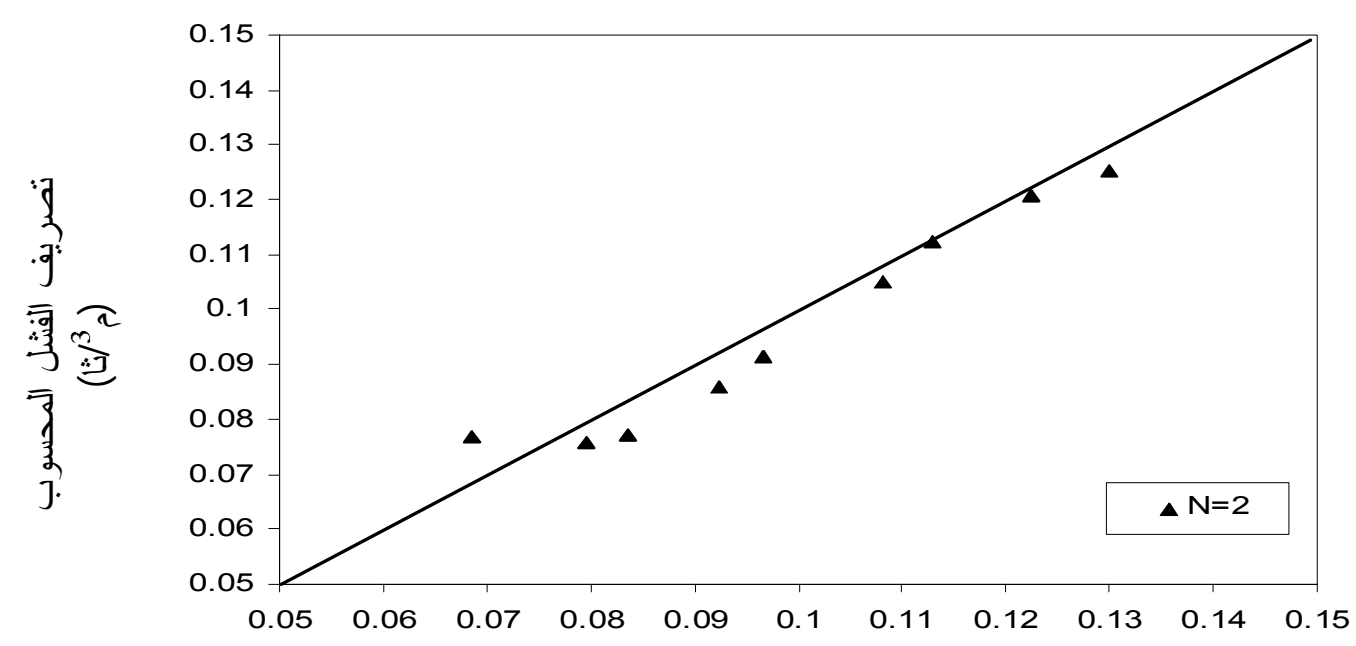

تصريف الفشل المقاس (مُ3/

الثكل (5 - ب): مقارنة بين قيم تصاريف فثل السلال الحصوية المحسوبة من المعادلة (10) و المقاسة مختبرياً

5. الطريقة التصميمية لحساب تصريف فشل السلال:

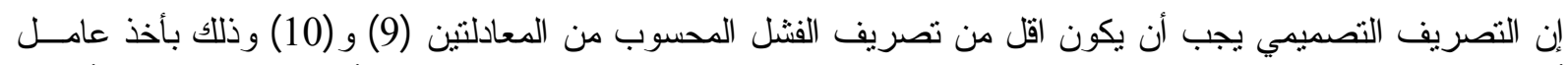

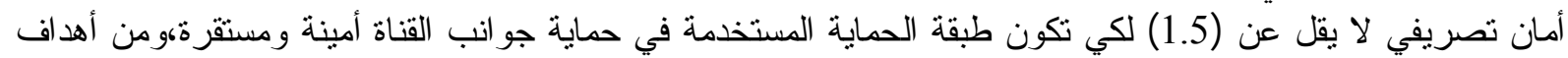

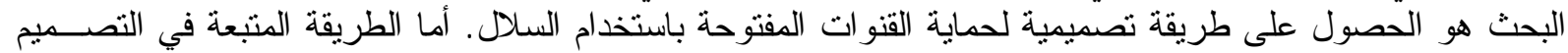

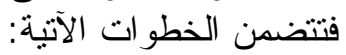
يحدا التصريف الأقصى الذي يمر في القناة الدر اد حمايتها عن طريق إجر اء در اسة شاملة للموقع.

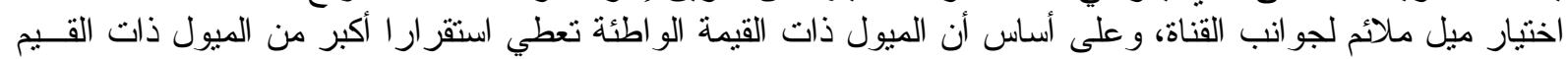
العالية. يحدد حجم الحجر أو الحصى (D $)$ المستخدم في ملئ السلدل ، ويفضل أن يكون متو افرأ في موقع العمل أو قريباً منه؛

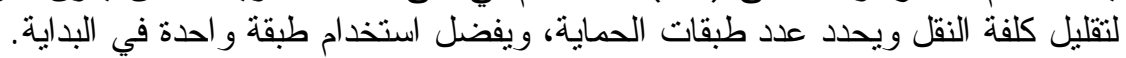

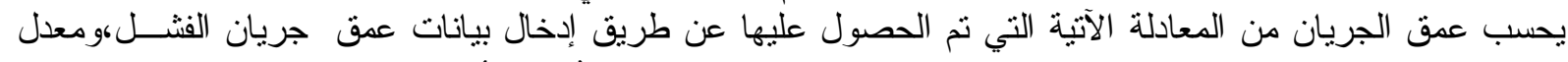
قطر الحجر ،وميل جو انب القناة ولحالتي الحماية بطبقة وطبقتين في برنامج (SPSS) الإحصائي:

$\mathrm{y}=0.771 \mathrm{D}_{\mathrm{m}}^{0.34} \mathrm{~S}^{0.12}$ 


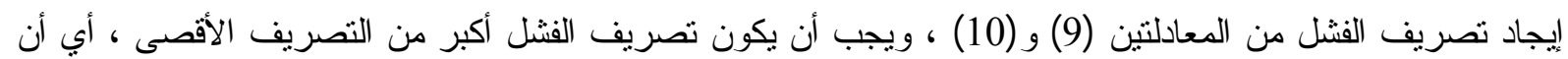

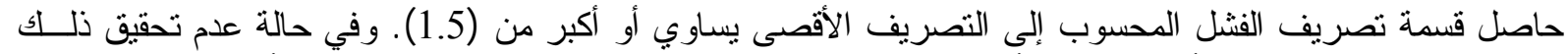

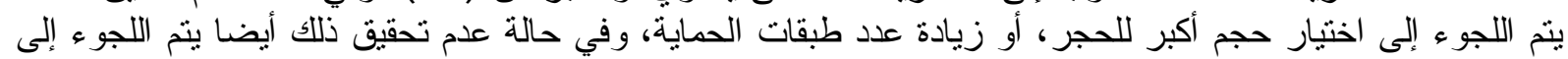
تغيير ميل جو انب القناة.

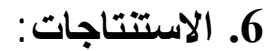

أن أهم الاستنتاجات التي تم النتاته التوصل إليها من هذا البحث هي :

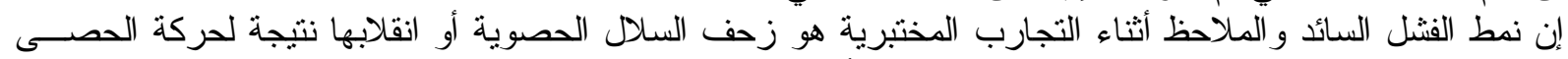

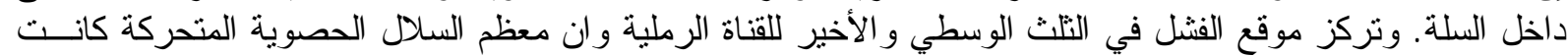

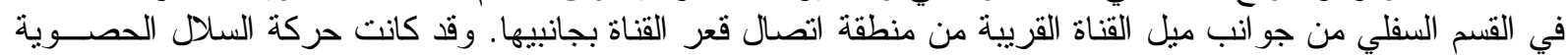
عثو ائية وغير منتظمة بحيث لا يمكن توقع عدد السلال المتحركة، موقعها أو زمن حدوث التئ الحركة أثناء إجر اء التجربة.

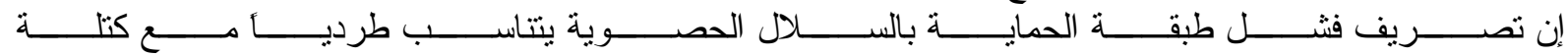

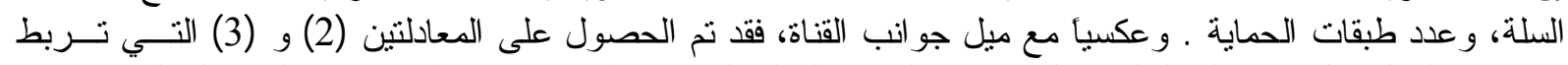

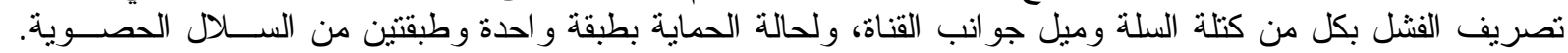

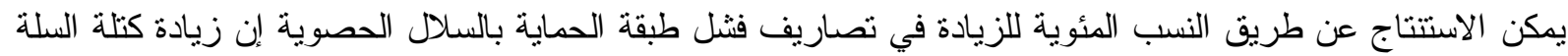

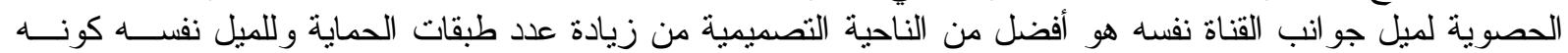

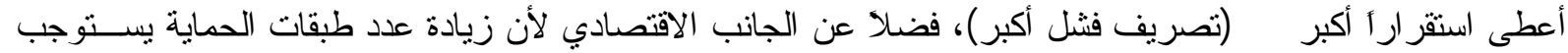
كلفة أكبر من كلفة تغيير كتلة السلة الحصوية.

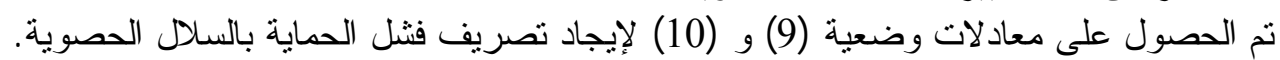

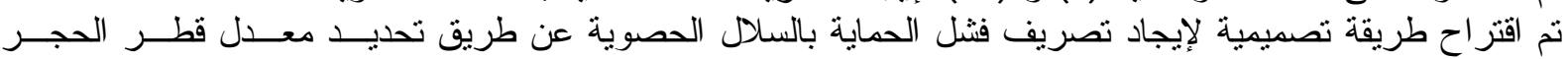
المستخدم في ملئ السلاح.

\section{المصادر}

1. Maynord, S. T., Ruff, J. F. and Abt., S. R., (1989), "Riprap Design”, J. Hydr. Eng., ASCE, 115 (7), 937-949.

2. Maynord, S. T., (1995), "Gabion-Mattress Channel-Protection Design", J. Hydr. Engrg. , ASCE, 121 (7), 519-522.

3. Stefano, C. D., and Ferro, V., (1998), "Calculating Average Filling Rock Diameter for Gabion-Mattress Channel Design”, J. of Hydr. Engrg. ASCE, Vol. 124 No. 9, 975-978.

4. Stevens, M. A., Lewis, G. L. and Simons, D. B., (1976), "Safety Factors for Riprap Protection", J. of Hydr. Div., ASCE, 102 (HY5), 637-655.

5. Dawood, B. K., (1999), "Laboratory Study on the Stability of Earth Weirs Protected by Gabions", Ph.D. Thesis, Department of Irrigation and Drainage Engineering, Mosul University, Mosul, Iraq (In Arabic).

6. Hanson, G. J., Lohnes, R. A. and Klaiber, F. W., (1986), “Gabions Used in Stream GradeStabilization Structures", Transportation Research Record, No. 1037, 35-42.

7. Technical Paper, (1987), "Maccaferri Gabions", Printed by Reno Grafica Balogna, Italy.

8. Technical Paper, (2001), "Gabions Baskets and Rock Matresses", Printed by GEOTAS, 14 Chesterman Street Moonah Tasmania.

9. Herman, J. K., (1984), "Scour Due to Riprap and Improper Filters", Proc. Hydr. Div, ASCE, 110 (HY10), 1315-1324.

10. Smith, K. V. H., (1979), "Model Testing of Weirs", Report on a Study Made in Collaboration with Sir William Halcrow and Partners, Swindan, February.

11. Ahmed, A. F., (1988), "Stability of Riprap Side Slopes in Open Channels", Ph. D., Thesis, Southampton University, England.

$$
\text { تم اجراء البحث في كلية الهنذسة - جامعة الموصل }
$$

